\title{
Comprender y gestionar el panorama crítico en América Latina y el Caribe
}

\author{
Understanding and managing critical issues \\ in Latin America and the Caribbean
}

María Belén Canto ${ }^{1}$

Fecha de recibido: 1 de julio de 2020

Fecha de aceptado: 11 de junio de 2021

\section{Resumen}

La manifestación de la epidemia de COVID-19 en América Central y en América del Sur, ha sido calificada por la Organización Mundial de la Salud como la más compleja del mundo. A tal punto es su impacto en alcance, dimensión e intensidad, que algunos expertos reconocen en dicha pandemia el mismo efecto demoledor que trajo aparejado la Segunda Guerra Mundial. La llegada del virus al escenario regional ha dejado al descubierto las graves insuficiencias en materia alimentaria, salud y bienestar que América Latina y el Caribe, que aún no se logra superar. La gran preocupación no es sólo el grave retroceso en los logros alcanzados sino también las implicaciones del COVID-19 en la configuración de un nuevo orden, que amenaza con ser menos integrado e inclusivo.

Palabras clave: América Latina y el Caribe, COVID- 19, VUCA, Agenda 2030.

1 N/A. Geógrafa especializada en Defensa Nacional, Ciencias Militares y Estrategia de Seguridad Nacional, Argentina, correo electrónico: cantomariab@gmail.com. 


\section{Abstract}

The manifestation of the COVID-19 epidemic in Central and South America has been rated by the World Health Organization as the most complex in the world. To such an extent is its impact in scope, dimension and intensity that sorne experts recognize in the pandemic the same devastating effect that World War II brought with it. The arrival of the virus on the regional scene has exposed the serious insufficiencies in food, health and well-being that Latín America and the Caribbean has not yet managed to overcome. The great concern is not only the serious setback in the achievements made, but also the implications of COVID-19 in shaping a new order, wh ich threatens to be less integrated and less inclusive.

Key words: Latin America and the Caribbean, COVID- 19, VUCA , Agenda 2030.

\section{La antesala al COVID-19}

Al leer el contexto de América Latina y el Caribe a la llegada de la pandemia, se observa que el escenario regional ya se enfrentaba a un panorama bastante crítico marcado por condiciones y situaciones de volatilidad, incertidumbre, complejidad y ambigüedad. Estos cuatro elementos conforman el acrónimo VUCA - por sus siglas en inglés-, instaurado por el U.S. Anny War College para describir el mundo surgido tras el fin de la Guerra Fría; desde entonces se utiliza de forma generalizada para reafirmar la significación estratégica del análisis que contempla las condiciones bajo las que se planifica, se toman decisiones, se gestionan riesgos y se resuelven problemas (Johansen, 2007).

Considerando estos elementos, partiendo por la volatilidad, se advierte que la naturaleza y dinámica del cambio impuesto por los shocks externos de la economía global han reproducido en el escenario latinoamericano lo que el Banco Mundial (BM) reconoce en los últimos años, como un débil desempeño económico con bajo crecimiento promedio. Los niveles de informalidad, los recursos limitados e instrumentos condicionados que caracterizan a las economías de la región hacen que América Latina y el Caribe no tengan el espacio 9cal del que gozan las economías avanzadas para hacer frente a la crisis. En grandes segmentos de la población, muchos hogares "viven al día" y no disponen de los recursos básicos necesarios para afrontar el confinamiento (Banco Mundial, 2020).

La falta de predictibilidad o incertidumbre gira entorno tanto a la disminución global de la producción como a la exposición a desastres naturales que devastan territorios enteros y afectan las economías nacionales 
de la región. Durante el año fiscal 2018, el BM aprobó préstamos orientados a inversiones en educación, salud y otras áreas del capital humano por una cifra que ronda los 4300 millones de dólares, emitiendo por primera vez bonos denominados "catastróficos" que superaron los 1300 millones a naciones como Chile, Colombia, México y Perú (Banco Mundial, 2020).

Estas acciones exponen parte del trabajo e inversión que la región hace tiempo viene desarrollando en la búsqueda de mejorar la capacidad de gestionar y afrontar el escenario complejo que experimenta la mayoría de sus países. La multiplicidad de fuerzas que surgen entorno a desastres naturales, trastornos económicos, violencia y crimen organizado sacuden fuertemente a Latinoamérica, atravesada por una crisis migratoria que registra desde el 2015 la movilización de casi 5 millones de personas.

A esto se suma la agitación social vivida el pasado 2019 a través de diferentes protestas que, si bien radican en diversos motivos, todas denuncian las desigualdades e injusticias crónicas que persisten en la región. Venezuela, Haití, Ecuador, Chile, Bolivia y Colombia fueron los escenarios de las movilizaciones más intensas que se cobraron la vida de muchos de los manifestantes.

En términos de ambigüedad, la distorsión de la realidad causada por la manipulación de las tecnologías digitales para propagar desinformación y generar polarización política - potencial para malentendidos y condiciones de confusión- se traduce en el lamentable progresivo debilitamiento de las instituciones esenciales y las normas políticas tradicionales (Levitsky y Ziblatt, 2018).

Este panorama crítico revela cuán difícil es para América Latina y el Caribe alcanzar la meta de una sociedad más inclusiva, próspera y sostenible a la luz de los Objetivos de Desarrollo Sostenible (ODS), trazados en la Agenda 2030 adoptada por la Organización de las Naciones Unidas en 2015 bajo la consigna "mejorar la vida de todos, sin dejar a nadie atrás". De hecho, el informe final de 2019 producido Comisión Económica para América Latina y el Carie (CEPAL), indica que el período 2014-2020 podría ser el septenio con el menor crecimiento económico durante los últimos setenta años (Naciones Unidas, 2016).

Asimismo, en el plano del estado de la seguridad alimentaria y la nutrición, el informe conjunto de Naciones Unidas en 2019 (FAO, 2019), indica que previo a la crisis del COVID-19- el hambre aflige a 42,5 millones de personas en América Latina y el Caribe. Se asocia el aumento de la pobreza y la desigualdad con la desaceleración económica de la región, según señaló el representante regional de la FAO, Julio Berdegué:

Durante los primeros 15 años de este siglo, América Latina y el Caribe redujo la subalimentación a la mitad. Pero desde 2014 el hambre ha ido aumentando, 
[...] tenemos que rescatar, en promedio, a más de 3,5 millones de personas del hambre cada año desde ahora hasta 2030 si queremos alcanzar la meta de hambre cero del Objetivo de Desarrollo Sostenible.

El aumento de la inseguridad alimentaria severa no es el único indicador tradicional de la subalimentación. Así como el hambre lleva años sin disminuir, la obesidad en Latinoamérica sigue creciendo como si ambas fueran las dos caras de una misma moneda. Consciente de que el sobrepeso y la obesidad han alcanzado proporciones epidémicas en la región de las Américas, la OMS aprobó para el período 2014-2019 diferentes planes de acción regionales sobre la nutrición en la salud, la prevención de la obesidad en la niñez y la adolescencia, y el desarrollo.

Estos planes han formado parte de un sistema de alerta anticipada adoptados por la OMS (2014), como medidas oportunas para reducir riesgos. Sin embargo, la imposibilidad de un considerable grupo de hogares de costear la canasta básica alimentaria ha derivado en un patrón de consumo poco saludable; actualmente se estima que por cada persona que sufre hambre, más de seis personas sufren sobrepeso en la región.

Según las condiciones exhibidas por los informes oficiales, el panorama del escenario regional ya resultaba poco alentador antes de la llegada de la pandemia del COVID-19. Así lo expresa Daniel Zovatto, Director Regional para América Latina y el Caribe de IDEA Internacional, "los hechos confirman que, para la región, 2019 fue un año económicamente decepcionante, electoralmente intenso, socialmente crispado y con una gobernabilidad compleja" (Zovatto, 2020, p. 1).

\section{Contexto actual en perspectiva}

Para cuando se registró el primer caso de COVID-19 en América Latina y el Caribe -Brasil, 26 de febrero de 2020- la región tuvo la posibilidad de anticiparse y seguir las líneas de acción aplicadas por aquellos países que ya hacían frente a la pandemia en su máxima expresión (CEPAL, 2020). Sin embargo, la alta vulnerabilidad del escenario regional, y la reacción tardía de algunos gobiernos para adoptar medidas efectivas, favoreció el ingreso acelerado del virus y su propagación.

En el contexto actual, gestionar la crisis por la que atraviesa todo el escenario regional implica un análisis en perspectiva a corto, mediano y largo plazo, que logre comprender en conjunto sus dimensiones política, económica, social y ambiental. En este esfuerzo, más allá de las prácticas adoptadas por otros países, puede tomarse como referencia el conocimiento adquirido a través de lo que fue la mayor pandemia del siglo XX.

"La gran epidemia”, también llamada "gripe española”, ha sido registrada como la peor pandemia global de la historia moderna por concentrar una 
elevada mortalidad en un corto período de tiempo, transcurrido entre los años 1918 y 1920. Diferentes publicaciones advierten que en 1917 la enfermedad ya se había presentado en un campamento militar de la ciudad de Kansas, en los Estados Unidos de América, y se propagó de manera alarmante a lo largo de todo el mundo a finales de la Primera Guerra Mundial. A diferencia de otros tipos de influenza que aquejaban principalmente a niños y ancianos, esta epidemia afectó a jóvenes y adultos saludables entre 20 y 40 años de edad, y también a animales domésticos, con síntomas similares a los hoy presenta el COVID-19.

La mayoría de las personas fallecidas en ese entonces, estimadas entre 50 y 100 millones en total, fue a consecuencia de una neumonía bacteriana secundaria por falta de antibióticos disponibles. Las medidas sanitarias tomadas por los gobiernos iban desde la desinfección de lugares públicos, suspensión de clases y de eventos masivos, prohibición de importaciones, el uso de mascarillas de telas hasta el aislamiento social, principalmente de aquellas personas que pudieran ser un foco de propagación. Se observó que cuanto mayor contacto había entre la gente, más se reproducía el virus.

En el trascurso de su evolución, puede apreciarse que dicha epidemia registró tres oleadas o brotes consecutivos. En lo que se conoce como la segunda oleada, cayó la mayor parte de las víctimas mortales concentrado en un breve lapso de 13 semanas. Para cuando se manifestó la tercer y última oleada gran parte de la población ya se encontraba inmunizada. El esfuerzo médico de la época se centró en brindar una respuesta a las causas e informar acerca de su avance y consecuencias. En 1919 se logra controlar dicha pandemia y se da por terminada en 1920, cuando el virus desaparece por sí solo. Hubo que esperar hasta 1943 para descubrir su cepa $-\mathrm{A} / \mathrm{H} 1 \mathrm{~N} 1-$, y su secuencia genética logra descifrarse recién en el año 2005.

A través del análisis crítico de dichos factores puede observarse como lección aprendida, por un lado, que la campaña de educación en higiene resultó altamente efectiva en los lugares donde ésta se promovía. Por otro lado, las personas y las poblaciones pobres fueron los estratos que más sufrieron negativamente las consecuencias de la gran epidemia de la historia moderna, y que ésta no llega a su fin sino hasta que el virus que la originó logró extinguirse por sí sólo.

Salvando las distancias, en lo que respecta a los avances en términos de ciencia y tecnología en el último siglo, ambas realidades encuentran parangón tanto en las medidas preventivas como en las recomendaciones sanitarias aplicadas y en que son las poblaciones vulnerables las más afectadas. En el escenario regional, el impacto del COVID-19 puede discriminarse en los diversos grupos de población al igual que la capacidad de respuesta de los diferentes países. 
La pandemia llega a América Latina y el Caribe en un contexto de bajo crecimiento $\mathrm{y}$, sobre todo, de alta desigualdad y vulnerabilidad, en el que se observan tendencias crecientes en la pobreza y pobreza extrema, un debilitamiento de la cohesión social y manifestaciones de descontento popular (CEPAL, 2020).

En este contexto, resulta imprescindible comprender que las decisiones tomadas por los gobiernos en lo inmediato repercutirán en la sostenibilidad financiera de sus países a largo plazo. Gestionar en una coyuntura de limitado espacio fiscal exige políticas de mayor alcance y profundidad bajo una lógica de protección colectiva e igualdad, sensible a las diferencias. Por esta razón, la perspectiva macroeconómica para América Latina y el Caribe de evitar otra década perdida requerirá de no descuidar los ámbitos más vulnerables en los que incide la pandemia a nivel microeconómico.

Las medidas de confinamiento necesarias para frenar la propagación del COVID-19 acarrean una dramática pérdida de ingresos que se traduce de manera directa en la interrupción de la cadena de pagos, pérdida de empleos y una fuerte contracción de remesas del consumo, especialmente en la capacidad de la población para costear necesidades básicas. Sobre la base del Banco de Datos de Encuestas de Hogares -BADEHOG_, que arroja una caída del 5,3\% del PIB y un crecimiento del desempleo de 3,4 puntos porcentuales, la CEPAL proyecta que el aumento de la pobreza y la pobreza extrema en América Latina en el 2020 afectará a más del 35\% de la población de la región, comprometiendo a casi 300 millones de personas (CEPAL, 2020, p. 2).

Según informó la Organización Internacional del Trabajo (OIT), las estadísticas del mercado laboral estimadas en 2018 revelan una alta proporción de empleos informales para la región, solo el $47,4 \%$ de los ocupados aportaba al sistema de pensiones y más del $20 \%$ de los ocupados como trabajadores informales ya se encontraban en situación de pobreza (OIT, 2018).

La precariedad laboral en la que se encuentra un amplio estrato de la población hace que una proporción considerable de hogares vivan al día para suplir sus necesidades básicas, aún sobre la base del endeudamiento. Esto significa que no poseen margen de ahorro para enfrentar el confinamiento, están imposibilitados para continuar el trabajo de manera remota, sin seguro social de desempleo ni cobertura sanitaria, "solo ocho países latinoamericanos y tres caribeños cuentan con seguro de desempleo" (CEPAL, 2020, p. 6).

El deterioro de la situación económica general como consecuencia del confinamiento también impacta fuertemente sobre muchos trabajadores formales al ver reducidos sus ingresos de manera parcial o total. La caída significativa de éstos podría empujarlos hacia un sobreendeudamiento y la pérdida posterior de los activos en micro, pequeños y medianos 
emprendimientos, provocando una movilidad económica descendente, principalmente en los estratos medios-bajos. En tanto los estratos mediosaltos y altos serían los menos afectados dado que podrían disponer de la liquidación de activos para sostener, aun a corto plazo, sus condiciones de vida.

Entre las poblaciones más afectadas por los impactos socioeconómicos del COVID-19 figuran los niños, niñas, adolescentes y jóvenes. Según se desprende del análisis de UNICEF y la ONG Save the Children, el 22\% de esta franja etaria pasará a engrosar las filas de la pobreza en América Latina y el Caribe. La suspensión de las actividades educativas de manera presencial no garantiza que las alternativas desarrolladas a través de plataformas digitales estén al alcance de todos los alumnos en condiciones de igualdad y calidad, en particular para aquellos que demandan una educación especial.

La dificultad de continuar los estudios profundizará la brecha digital educativa. El abandono escolar en el corto plazo se traducirá en el futuro inmediato en un escenario más adverso respecto a las oportunidades de inserción laboral para las generaciones que cuenten con menos recursos. Al considerar la perspectiva a mediano y largo plazo, ésta dificultad seguiría reproduciendo el círculo vicioso de la informalidad laboral que no concurre al logro de alcanzar un crecimiento inclusivo y un desarrollo sostenible.

La matriz de desigualdad social en la región se ve agravada en las áreas urbanas marginales, donde las condiciones de las viviendas y la carencia de los servicios básicos para mantener un nivel óptimo de salubridad, sobreexponen la población al riesgo de enfermar. Más allá de las personas en situación de pobreza, las poblaciones y los ámbitos en que incide la pandemia son amplios y diversos como se enumera en la Tabla 1. Entre estas poblaciones, los adultos mayores enfrentan la limitación de sus capacidades para responder al aislamiento y a la enfermedad.

Aunque el confinamiento resulta ser una de las principales medidas para frenar el avance de la pandemia, los costos que se deberán cubrir por sostenerlo serían altos. El Premio Nobel de Química, Michael Levitt, afirma que el daño ocasionado por el confinamiento será mucho mayor que cualquier otro que frente el COVID-19 se haya evitado. En el corto plazo, según Levitt, la medida de aislamiento social puede salvar vidas pero cerrar el mundo tiene un precio económico grande y el daño social - por abuso doméstico, divorcios, adicciones, suspensión de tratamientos médicos, entre otros- será desmedido (Levitt, 2020).

De esta forma, el impacto de la epidemia del COVID-19 acrecienta el difícil contexto del escenario regional, poniendo en evidencia las limitaciones de las políticas económicas y de protección social que se han desarrollado hasta el momento. Por ende, una buena gobernanza deberá contemplar la redefinición 
del sistema de garantías universales, con políticas de mayor alcance y profundidad, de modo que los ancianos no pierdan la vida ni los jóvenes el futuro.

Tabla 1. Poblaciones más afectadas por los impactos socioeconómicos del COVID-19

\begin{tabular}{ll}
\hline \multicolumn{1}{c}{ Poblaciones } & Ámbitos en que incide la pandemia \\
\hline Mujeres & Salud física y mental \\
Estratos de ingresos bajos y medios-bajos & Nutrición \\
Trabajadores informales & Educación Ingresos laborales \\
Trabajadoras domésticas remuneradas & Trabajo infantil \\
Niños, niñas y adolescentes & Acceso a servicios básicos (agua, \\
Jóvenes & gas, saneamiento, electricidad, \\
Personas mayores & tecnologías digitales) \\
Población rural & Trabajo de cuidado no remunerado \\
Pueblos indígenas & Violencia intrafamiliar \\
Afrodescendientes & \\
Personas con discapacidad & \\
Migrantes & \\
Personas en situación de calle & \\
\hline
\end{tabular}

Fuente: Comisión Económica para América Latina y el Caribe (CEPAL) en "El desafio social en tiempos del COVID-19", Informe Especial COVID-19, núm. 3, 12 de mayo de 2020.

\section{Repensar el modelo}

La magnitud de la crisis en la que se encuentra sumergida América Latina y el Caribe, plantea el desafío de intervenir oportunamente para evitar que ésta se siga profundizando y, aún más, poder revertirla. Al efecto, un elemento central es la Agenda 2030, entendida como la hoja de ruta aceptada por el conjunto de la comunidad internacional para alcanzar una sociedad más inclusiva y sostenible. La gravedad de la situación, sumada al debilitamiento por el que atraviesan las instituciones hace que "según la perspectiva y los autores que uno elija [puedan encontrase], datos y argumentos para el optimismo y para el pesimismo sobre el futuro a corto, medio y largo plazo de la humanidad" (Sahagún, 2020, p. 63).

En términos de capacidad de respuesta, Paul Krugman reconoce que las implicancias del COVID-19 conducen a cambios psicológicos y perceptivos muy diferentes que alterarán el mundo, haciéndolo más débil, menos integrado e inclusivo en sentido político y financiero. Por un lado, el economista advierte 
que el impacto económico es muy severo, exacerbó algunas situaciones que estaban en tensión antes de la pandemia y aún no se sabe cuánto durará.

Por otro lado, Krugman reconoce que la acusación de Estados Unidos a la OMS de ceder hacia intereses poderosos, y la posibilidad de cortar lazos, ha socavado la credibilidad en las instituciones haciendo muy difícil para los países volver al tipo de negociación de buena fe y confianza, en ausencia de una fuerza estabilizadora global (Krugman, 2020).

En esta misma línea, apoyado en su extensa trayectoria en análisis de la desigualdad económica y del desarrollo en el mundo, el economista Branko Milanovic prevé que la epidemia provocará cambios en las cadenas globales de producción, que añadirá más tensión a las relaciones políticas, deteriorando la voluntad de cooperación entre los países. Él mismo insiste en que los problemas sociales no desaparecen por alcanzar un elevado crecimiento económico dado que por sí sólo es un simple número promedio. Aún en medio de condiciones de crecimiento, puede persistir la desigualdad, generando niveles de estratificación dentro de la sociedad diferenciados entre aquellos que tienen acceso a oportunidades de los que no (Milanovic, 2020). Por ello, el economista es partidario de la desconcentración del capital a través de medidas que otorguen mayores ventajas a pequeños inversores, como la mejora del sistema impositivo y la garantía de una educación de calidad para todos, entre otras.

Bajo una óptica similar, ante la crítica situación que se percibía hacia finales de la Segunda Guerra Mundial, el científico social y economista político Karl Polanyi descubre a través de sus investigaciones de antropología económica las estrategias implementadas por las comunidades primitivas que resultaron ser exitosas para su organización. En un intento por transformar la visión financiera, alerta sobre los efectos destructivos de la subordinación de los países en desarrollo a los requerimientos de la economía de mercado, de modo que pudiera "salvar a la humanidad de catástrofes nunca antes experimentadas"; logra identificar patrones de integración que considera universales, factibles de ser encontrados en todos los sistemas de organización de la vida económica (Polanyi, 1944).

A través de esos pabones, Polanyi postula tres modelos basados en mecanismos de reciprocidad, redistribución e intercambio que ordenan la dinámica económica de ciertas comunidades primitivas. Según indica, tales patrones no derivan de la suma de actos individuales sino que condicionan la existencia de instituciones específicas para su desempeño (Polanyi, 2014).

Esto último adquiere especial relevancia en la coyuntura actual, dado que el desconcierto y la zozobra que genera la pandemia despierta manifestaciones de desconfianza que ponen en riesgo la cohesión social. Esto se ve agravado por el hecho de que "la pandemia ha puesto al descubierto 
no solo las limitaciones estructurales del modelo económico vigente, sino también las fallas e insuficiencias de los sistemas de protección social y de los regímenes de bienestar en general" (CEPAL, 2020, p. 21). De ahí la urgencia de repensar un modelo para América Latina y el Caribe que esté acompañado del fortalecimiento de la institucionalidad democrática como piedra angular para el desarrollo de políticas universales, redistributivas y solidarias.

Al revisar los ciclos experimentados por la región en las últimas cuatro décadas, la CEPAL estima que el aumento de la pobreza proyectado para 2020 implicará un retroceso de 13 años. A través de estos ciclos, tal como lo refleja el Gráfico 1, puede observarse que la inacción frente a la crisis de la deuda de 1980 derivó en el incremento de la pobreza en la región hasta alcanzar niveles muy significativos, y se debió esperar 25 años para retomar a los niveles de pobreza previos a dicha crisis. En contraste, resulta evidente la importancia de las estrategias de gasto público social contracíclico y de las políticas sociales aplicadas para moderar los efectos de la crisis financiera internacional de 2008 sobre las economías reales, lo cual logró frenar el aumento del desempleo y la pobreza en la regió para ese entonces.

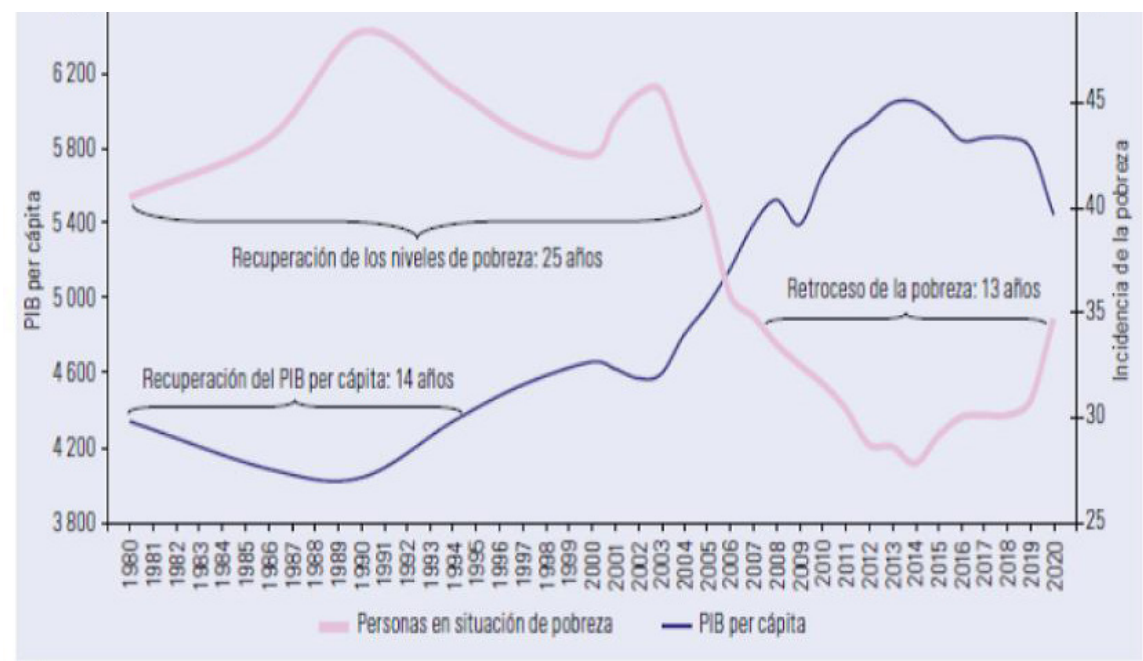

Gráfico 1. América Latina (18 países): PIB per cápita e incidencia de la pobreza, 1980-2020.

Fuente: Comisión Económica para América Latina y el Caribe (CEPAL) en "El desafío social en tiempos del COVID-19", Informe Especial COVID-19, núm. 3, 12 de mayo de 2020.

Sobre la base del Banco de Datos de Encuestas de Hogares (BADEHOG). Los países considerados son: Argentina, Bolivia (Estado Plurinacional de), Brasil, Chile, Colombia, Costa Rica, Ecuador, El Salvador, Guatemala, 
Honduras, México, Nicaragua, Panamá, Paraguay, Perú, República Dominicana, Uruguay y Venezuela (República Bolivariana de). Las cifras de 2019 son datos preliminares; las cifras de 2020 son proyecciones.

Por esa razón, frente a la gravedad que el COVID-19 le asigna a toda la región, la CEPAL propone que los gobiernos apliquen medidas emergentes de protección social y refuercen las ya existentes a los efectos de garantizar un ingreso que permita satisfacer las necesidades básicas de los hogares y sostener el consumo. Entre las principales medidas de apoyo a la población, se encuentran la entrega de alimentos, transferencias monetarias, alivios tributarios, acceso a créditos, facilidades de pago y control de precios.

El alcance de estas medidas requiere implementar políticas sociales de calidad que contemplen más allá de las personas en situación de pobreza y vulnerabilidad, bajo una perspectiva enfocada en lograr una reactivación sólida una vez superada la pandemia.

Su implementación se enfrenta al limitado espacio fiscal que poseen los países de América Latina y el Caribe, y trae aparejado costos adicionales asociados a problemas operativos tal como la falta de bancarización de un importante segmento de la población. Hasta el momento, según estima la CEPAL los países que cuentan con mayor cobertura absoluta de hogares son: Brasil (38,2 millones), Colombia (11,3 millones), Argentina (8,4 millones) y Perú (4,8 millones).

De este modo, la planificación, diseño e implementación de medidas de protección social demanda eficacia, calidad y buena orientación de la intervención del Estado para proteger el gasto público social. En la gestión de toda buena planificación resulta indispensable "contar con sistemas de información, seguimiento y evaluación de las prestaciones sociales, incluidos registros de la población destinataria o potencialmente destinataria que sean lo más amplios y actualizados posible” (CEPAL, 2020, p. 20).

En términos teóricos, planificar teniendo en cuenta los criterios comúnmente asociados con el acrónimo SMART - por sus siglas en ingléspermite visualizar la importancia de los objetivos y sortear la dificultad de establecerlos. Así, resultan imprescindibles cinco criterios fundamentales para ser aplicados en toda planificación y comprobar su correcto funcionamiento:

- Especificidad: apuntar a un área determinada para mejorar.

- Medición: cuantificar o al menos sugerir un indicador de progreso.

- Asignación: especificar quién o qué área lo hará.

- Realización: indicar qué resultados pueden lograrse de manera objetiva, dados los recursos disponibles.

- Temporalidad: especificar el tiempo en que pueden lograrse los resultados. 
Aunque en ciertas situaciones intentar la cuantificación puede resultar poco realista, aplicar criterios de medición como indicadores de progreso permite evaluar la gestión para que ésta pueda ser mejorada.

Por ello, para comprender y gestionar los impactos del COVID-19 y salir de la crisis instalada en la región, es necesario repensar el modelo de desarrollo contemplando estos parámetros, de modo que se pueda avanzar más allá de simples soluciones cosméticas y temporales. "Construir el Estado de bienestar y sistemas de protección social universal es clave para evitar otra década perdida" (CEPAL, 2020, p. 20), de ahí la necesidad de repensar sobre la base de un pacto social centrado en el bienestar y la protección igualitaria de los derechos y las condiciones de toda la población, en las distintas etapas del ciclo de vida.

En efecto, conquistar la meta de un verdadero desarrollo sostenible es una tarea compleja que requiere internalizar la perspectiva de largo plazo y el esfuerzo mancomunado del Estado y la sociedad en su conjunto. Y si bien pude considerarse como un ideal, impulsar el círculo virtuoso que conduce a la sostenibilidad financiera debería contemplar los patrones de integración basados en los mecanismos de reciprocidad, redistribución e intercambio. Por el contrario, de prevalecer una óptica individualista resultaría en otro nuevo modelo inviable, aunque como sostiene el profesor de ética Galo Bilbao, el gesto más inteligente de un egoísta es ser solidario.

\section{A modo de reflexión}

Sin duda los gobiernos afrontan el gran desafío de proteger a su población contra el avance tanto del COVID-19 como del deterioro social y económico que azota a la región. Existen muchos obstáculos para revertir la desigualdad y concretar avances significativos en el desarrollo sostenible de América Latina y el Caribe. Construir un Estado de bienestar y sistemas de protección social universal sobre patrones de integración demanda un cambio de paradigma que deje de lado corrientes individualistas y recupere la responsabilidad colectiva del propio valor, del respeto y reconocimiento recíproco.

Reivindicar la figura e importancia del Estado de bienestar exige de acciones que desconstruyan la forma tradicional de la política de maná. Seguir atrapado en esa percepción conlleva un alto costo social, principalmente para las últimas y próximas generaciones. Para ello, como dijo alguna vez Henry Ford, "si hay un secreto del éxito, reside en la capacidad para apreciar el punto de vista del prójimo y ver las cosas desde ese punto de vista así como el propio". Aprender a ponerse en el Jugar del otro, permite conocer acerca de lo que el prójimo necesita y quiere, y permite así acompañarlo en el desarrollo de aquellas prácticas que en suma llevan a descubrir el valor, la habilidad, el esfuerzo y la constancia para corregir la mala fortuna y prosperar en todos 
los órdenes de la vida, empezando por la familia como principal núcleo de pertenencia y el espacio propio.

\section{Referencias}

Banco Mundial (BM) (2020). América Latina y el Caribe: panorama general. https://www.bancomundial.org/es/topic/poverty/overview

CEPAL, UN (2020). El desafio social en tiempos del COVID-19. Informe Especial COVID-19, núm. 3, ECLAC, Santiago. https://www.cepal.org/es/publicaciones/45527desafio-social-tiempos-covid-19

FAO (Organización de las Naciones Unidas para la Alimentación y la Agricultura) (2019). El estado de la seguridad alimentaria y la nutrición en el mundo. Protegerse frente a la desaceleración y el debilitamiento de la economía, Roma. http://www.fao.org/3/ca5162es/ca5162es.pdf

Johansen, B. (2007). Get There Early: Sensing the Future to Compete in the Present, (51-53), Benett-Koehler Publishers, San Francisco, CA.

Krugman, K. (2020). Entrevista Imagina el mundo. Coronavirus: nobel de Economía, te invita a intercambiar ideas sobre la crisis. BBC News Mundo. https://www.bbc.com/mundo/noticias-intern.acional-52875176

Levitsky, S. y Ziblatt, D. (2018). Cómo mueren las democracias, Ariel, Barcelona.

Milanovic, B. (2020). Los más ricos en Chile ganan como los más ricos de Alemania y los más pobres como en Mongolia, BBC News Mundo. https://www.bbc.com/mundo/noticias-52915848

Milanovic, B. (2016). Global Inequality: A new approach for the age of globalization, Harvard University Press.

Naciones Unidas. Objetivos y metas de desarrollo sostenible. https://www.un.org/ sustainabledevelopment/es/sustainable-developmentgoals/

Navarro Sanz, B. (2020). El impacto de la crisis de la COVID-19 en los Objetivos de Desarrollo Sostenible: ¿un retroceso sin precedentes en la Agenda 2030?, Documento de Opinión IEEE 78/2020. https://www.iee.es/publicacionesnew/documentos-de-opinion/2020/DIEEEO78_2020BEANAV_CovidODS.html

OIT (Organización Internacional del Trabajo ) (2018). Perspectivas sociales y del empleo en el mundo: tendencias 2018.

https://www.ilo.org/wcmsp5/groups/public/---dgreports/---dcomm/--publ/ documents/publication/wcms_631466.pdf

OMS (Organización Mundial de la Salud) (2014). Resolución CD53.RI3, Plan de acción para la prevención de la obesidad en la niñez y la adolescencia, $53^{\circ}$ Consejo Directivo 66, Sesión del Comité Regional de la OMS para las Américas, Washington, D.C.

Polanyi-Levitt, K. (2014). Los conceptos más impoltantes en el trabajo de Karl Polanyi y su relevancia contemporánea. Revista Economía y Desarrollo, 151(1), Universidad de La Habana.

Polanyi, K. (1989). La gran transformación, edición en castellano. La Piqueta, Madrid. 
Sahagún, F. (2020). El mundo en 2020. Panorama estratégico 2020. Instituto Español de Estudios Estratégicos (IEEE), Gobierno de España. http://www.ieee.es/ publicacionesnew/panorama-estrategico/2020/PANEST-2020.htm

Scarlett, Sara (23 de mayo de 2020). Lockdown was a waste of time and could kill more than it saved, claims Nobel laureate scientist at Stanford University. Daily Mail.com. https://www.dailymail.co.uk/news/article-8351649/Lockdownwaste-time-killsaved-claims-Nobel-laureate.html

UNICEF (Fondo de las Naciones Unidas para la Infancia). El nuevo coronavirus y el derecho a la educación.

https://www.unicef.es/educa/blog/nuevocoronavirus-derecho-educacion

Zobatto, D. (2020). El súper ciclo electoral latinoamericano 2017-2019: el voto de enojo en tiempos de fatiga democrática y malestar con la política. Análisis Carolina, 3(20).

https://www.fundacioncarolina.es/wp-content/uploads/2020/01/AC-3.20.pdf 